\title{
Clinicopathological significance of vascular endothelial growth factor, thymidine phosphorylase and microvessel density in colorectal cancer
}

\author{
YUTAKA KIMURA $^{1}$, SATOKO MOROHASHI ${ }^{2}$, TADASHI YOSHIZAWA ${ }^{1,2}$, TAKAHIRO SUZUKI $^{2}$, \\ HAJIME MOROHASHI ${ }^{1}$, YOSHIYUKI SAKAMOTO ${ }^{1}$, MOTOI KOYAMA ${ }^{1}$, AKIHIKO MURATA ${ }^{1}$, \\ HIROSHI KIJIMA $^{2}$ and KENICHI HAKAMADA ${ }^{1}$ \\ Departments of ${ }^{1}$ Gastroenterological Surgery, and ${ }^{2}$ Pathology and Bioscience, \\ Hirosaki University Graduate School of Medicine and Hospital, Hirosaki, Aomori 036-8562, Japan
}

Received October 28, 2014; Accepted July 28, 2015

DOI: $10.3892 / \mathrm{mmr} .2015 .4687$

\begin{abstract}
Colorectal cancer is a common malignant disease, the incidence of which is increasing worldwide, therefore, identifying novel prognostic factors to improve adjuvant therapeutic strategies or postoperative monitoring is required. Angiogenesis, which is assessed by microvessel density (MVD), is significant in tumor growth and metastasis. However, the association between angiogenesis and clinical outcome remains controversial. In the present study, 84 surgically resected cases of colorectal cancer were examined to clarify the clinicopathological significance of vascular endothelial growth factor (VEGF), thymidine phosphorylase (TP) and cluster of differentiation (CD)34 expression levels. VEGF expression was identified to be significantly correlated with TP expression $(\mathrm{r}=0.45 ; \mathrm{P}<0.0001)$ and MVD in the high VEGF expression group was observed to be significantly greater than that in the low VEGF expression group $(\mathrm{P}=0.0194)$. In the Dukes' stage D group, the MVD in the high TP expression group was significantly greater than that in the low TP expression group $(\mathrm{P}=0.0149)$. High VEGF expression was subsequently correlated with a short overall survival rate for patients exhibiting lymph node metastasis $(\mathrm{P}=0.0128)$; however, there was no significant difference in overall survival rate regarding the expression levels of TP and CD34. The results of the present study indicate that VEGF expression may serve as a prognostic factor for colorectal cancer patients exhibiting lymph node metastasis. Furthermore, angiogenesis, as assessed by MVD, is an important prognostic factor for tumor growth at the primary site.
\end{abstract}

Correspondence to: Dr Hiroshi Kijima, Department of Pathology and Bioscience, Hirosaki University Graduate School of Medicine and Hospital, 5 Zaifu-Cho, Hirosaki, Aomori 036-8562, Japan E-mail: hkijima@cc.hirosaki-u.ac.jp

Key words: vascular endothelial growth factor, thymidine phosphorylase, microvessel density, colorectal cancer

\section{Introduction}

Colorectal cancer is a common malignant disease, with an increasing incidence worldwide and remains one of the leading causes of mortality, globally (1). In recent years, it has become the leading cause of cancer-associated mortality in Japanese females (2). The TNM classification and Dukes' staging system are useful for determining the colorectal cancer stage in patients (3). However, these conventional staging procedures cannot precisely predict the cancer prognosis, as many patients at the same colorectal cancer stage experience various clinical outcomes. Therefore, the identification of novel prognostic factors to improve adjuvant therapeutic strategies or postoperative monitoring is required (4).

Angiogenesis, commonly assessed by the microvessel density (MVD), is involved in the formation of new blood vessels, and is important for tumor growth and metastasis $(5,6)$. The association between angiogenesis and the clinical outcome of colorectal cancer is currently controversial and inconclusive, although colorectal cancer has been one of the most widely investigated types of tumor (7-9). In a previous study, a regimen of combined chemotherapy with a monoclonal anti-vascular endothelial growth factor (VEGF) antibody resulted in improved patient survival (10). Therefore, angiogenesis in colorectal cancer is considered to be a particularly interesting research field.

VEGF is a potent angiogenic factor, which stimulates endothelial cell proliferation, survival and vascular maturation (10). Various studies have demonstrated that the VEGF expression level correlates with angiogenesis $(11,12)$ and tumor progression in colorectal cancer $(13,14)$; however, the prognostic value of VEGF expression levels in colorectal cancer remains to be fully elucidated.

Thymidine phosphorylase (TP), also termed platelet derived endothelial cell growth factor, is an essential enzyme for the activation of fluoropyrimidine, as well as an angiogenic factor $(15,16)$. TP exerts distinct and contradictory biological functions (17) that complicate the analysis of its contribution to predicting the response to therapy or the 
prognosis. Despite various studies regarding TP (18-24), the clinical applications of TP in colorectal cancer continue to be insufficient (25).

In the present study, the expression of VEGF, TP and cluster of differentiation (CD) 34 as a marker of MVD were examined in 84 cases of colorectal cancer. These factors were assessed to elucidate whether they are interrelated, and to establish whether expression of VEGF, TP and CD34 is correlated with clinicopathologic features and clinical outcomes.

\section{Materials and methods}

Patients and materials. Surgically resected tissues of 84 patients with colorectal cancer were analyzed at the Hirosaki University Hospital (Hirosaki, Japan) between January 2005 and December 2006, after obtaining informed consent from each patient to use their clinical records and pathology specimens. The present study was approved by the Research Ethics Committee of the Hirosaki University Graduate School of Medicine (Hirosaki, Japan). Survival data were obtained from hospital medical charts and by contacting patients or their families, and the median postoperative follow-up period was 1,027 (14-1,298) days. The series consisted of 55 males and 29 females with a median age of 66 years (range, 31-90 years). The patients had not received chemotherapy or radiation therapy prior to surgery. Forty-seven tumors were located in the colon and 37 tumors were in the rectum. Of the 84 cases, 35 were well-differentiated adenocarcinomas, 43 were moderately differentiated adenocarcinomas and six were poorly differentiated adenocarcinomas, mucinous adenocarcinoma, and signet-ring cell carcinoma The pathological stage of each case at the time of surgery was defined according to the TNM classification (3) and Dukes' classification (26) as follows: Dukes' stage A $(n=8)$, invasion is not yet through the bowel wall; Dukes' stage B $(n=26)$, invasion through the bowel wall; Dukes' stage $C(n=27)$, involvement of lymph node metastasis; and Dukes' stage $\mathrm{D}(\mathrm{n}=23)$ involvement of distant organ metastasis. The present study was retrospective and was conducted according to the principles of the World Medical Association Declaration of Helsinki 1964 (27).

Histopathological and immunohistochemical examinations. For histological examination, the pathology specimens were routinely fixed with formalin, embedded in paraffin, thin-sectioned $(4 \mu \mathrm{m})$, and stained with hematoxylin and eosin (all from Muto Pure Chemicals Co., Ltd., Tokyo, Japan). Each lesion was graded histologically according to the Japanese Classification of Colorectal Carcinoma (28). The degree of lymphatic (ly) and venous (v) invasion were classified into the following four categories: i) ly0/v0, no invasion; ii) ly1/v1, minimal invasion; iii) ly $2 / \mathrm{v} 2$, moderate invasion; and iv) ly $3 / \mathrm{v} 3$, severe invasion. The budding grade, defined as an isolated single cancer cell or a cluster composed of fewer than five cancer cells, was classified as follows: grade 0 , no budding; grade 1, 1-4 foci in one histological section; grade 2, 5-9 foci in one histological section; and grade 3, $\geq 10$ foci in one histological section (29).

In each case, one representative histological specimen at the deepest invaded area of the colorectal cancer lesion was selected for immunohistochemistry. Sections (thickness, $4 \mu \mathrm{m}$ ) were mounted on silane-coated glass slides (Muto Pure
Chemicals Co., Ltd.). The primary antibodies used for immunohistochemistry were rabbit anti-VEGF polyclonal antibody (1:100 dilution; cat. no. sc-152; Santa Cruz Biotechnology, Inc., Dallas, TX, USA), mouse anti-TP monoclonal antibody (clone 1C6-203; 1:500 dilution; cat. no. 1C6-203; Chugai Pharmaceutical Co., Ltd., Research Center, Kamakura, Japan) and mouse anti-CD34 monoclonal antibody (1:200 dilution; cat. no. M7165; Dako, Glostrup, Denmark). For antigen retrieval, sections were heated in a microwave oven for $20 \mathrm{~min}$ in $10 \mathrm{mM}$ citrate buffer (Muto Pure Chemicals Co., Ltd.). The staining was performed following a streptavidin biotin-peroxidase procedure using a Histofine ${ }^{\circledR}$ kit (Nichirei Biosciences, Inc., Tokyo, Japan) according to the manufacturer's instructions. All sections were incubated overnight at $4^{\circ} \mathrm{C}$. The sections were reacted with 3,3'-diaminobenzidine tetrahydrochloride (Merck Millipore, Darmstadt, Germany) and counterstained with hematoxylin.

Evaluation of immunohistochemistry. Staining patterns of VEGF and TP expression were divided into two groups: High, $\geq 50 \%$ of staining in the tumor cells; and low, $<50 \%$ of staining in the tumor cells.

MVD was assessed by counting the microvessels that were immunostained for the CD34 antigen under a light microscope (BX50 microscope; Olympus, Tokyo, Japan). The CD34-stained sections were carefully scanned at a magnification of $\mathrm{x} 4$ (low-power field) to identify the regions with the greatest number of microvessels (designated as 'hot spots') using a digital color camera system (DP70; Olympus). In each case, the three most vascularized areas within the tumors were selected and the individual vessels were counted under a magnification of x20 (high-power field). The mean count from each of the three regions was recorded for analysis as MVD and expressed as the number of vessels/high-power field (30). In addition, the specimens were divided into the following two groups: High, $\geq 81.33$ (mean value) vessels per high-power field; and low, $<81.33$ (mean value) vessels per high-power field.

Statistical analysis. Statistical analyses of immunostaining were performed using the $\chi^{2}$ test or Fisher's exact probability test and Bonferroni correction. Spearman's rank correlation test was used to assess the correlations between VEGF and TP expression. Survival curves were calculated using the Kaplan-Meier method and differences in survival were evaluated using the log-rank test. Excluding the Bonferroni correction, $\mathrm{P}<0.05$ were considered to indicate a statistically significant difference. All of the statistical evaluations were performed using the statistical software package StatView (version 5.0; SAS Institute, Inc., Cary, NC, USA).

\section{Results}

Immunohistochemical expression levels of VEGF, TP, and CD34. Representative immunohistochemical expression patterns of VEGF, TP, and CD34 are demonstrated in Fig. 1. The associations between clinicopathologic features and VEGF/TP expression levels, and MVD are summarized in Table I. No significant association was identified between VEGF and TP expression levels, and MVD for gender, tumor location, histological type, lymph node metastasis, 
Table I. Association between clinicopathologic features, VEGF and TP expression levels and MVD.

\begin{tabular}{|c|c|c|c|c|c|c|c|c|c|c|}
\hline \multirow[b]{2}{*}{$\begin{array}{l}\text { Clinicopathologic } \\
\text { feature }^{\mathrm{a}}\end{array}$} & \multirow[b]{2}{*}{$\begin{array}{l}\text { Cases } \\
\mathrm{n}=84\end{array}$} & \multicolumn{3}{|c|}{$\begin{array}{c}\text { VEGF } \\
\text { expression }\end{array}$} & \multicolumn{3}{|c|}{$\begin{array}{c}\mathrm{TP} \\
\text { expression }\end{array}$} & \multicolumn{3}{|c|}{ MVD } \\
\hline & & $\begin{array}{l}\text { High } \\
(\mathrm{n}=53)\end{array}$ & $\begin{array}{l}\text { Low } \\
(\mathrm{n}=31)\end{array}$ & P-value & $\begin{array}{l}\text { High } \\
(\mathrm{n}=55)\end{array}$ & $\begin{array}{l}\text { Low } \\
(\mathrm{n}=29)\end{array}$ & P-value & $\begin{array}{l}\text { High } \\
(\mathrm{n}=39)\end{array}$ & $\begin{array}{l}\text { Low } \\
(n=45)\end{array}$ & P-value \\
\hline Gender & & & & 0.27 & & & 0.15 & & & 0.11 \\
\hline Male & 55 & 37 & 18 & & 33 & 22 & & 29 & 26 & \\
\hline Female & 29 & 16 & 13 & & 22 & 7 & & 10 & 19 & \\
\hline Location & & & & 0.77 & & & 0.57 & & & 0.72 \\
\hline Colon & 47 & 29 & 18 & & 32 & 15 & & 21 & 26 & \\
\hline Rectum & 37 & 24 & 13 & & 23 & 14 & & 18 & 19 & \\
\hline Histological type & & & & 0.25 & & & 0.21 & & & 0.11 \\
\hline Well & 35 & 24 & 11 & & 23 & 12 & & 21 & 14 & \\
\hline Moderate & 43 & 27 & 16 & & 30 & 13 & & 16 & 27 & \\
\hline Poor/Other & 6 & 2 & 4 & & 2 & 4 & & 2 & 4 & \\
\hline Lymph node metastasis & & & & 0.13 & & & 0.84 & & & 0.15 \\
\hline pNO & 36 & 26 & 10 & & 24 & 12 & & 20 & 16 & \\
\hline pN1-4 & 48 & 27 & 21 & & 31 & 17 & & 19 & 29 & \\
\hline Lymphatic invasion & & & & 0.78 & & & 0.81 & & & 0.63 \\
\hline ly0-1 & 45 & 29 & 16 & & 30 & 15 & & 22 & 23 & \\
\hline ly2-3 & 39 & 24 & 15 & & 25 & 14 & & 17 & 22 & \\
\hline Venous invasion & & & & 0.57 & & & 0.76 & & & 0.37 \\
\hline $\mathrm{v} 0-1$ & 62 & 38 & 24 & & 40 & 22 & & 27 & 35 & \\
\hline v2-3 & 22 & 15 & 7 & & 15 & 7 & & 12 & 10 & \\
\hline Budding & & & & 0.88 & & & 0.41 & & & 0.21 \\
\hline Grade $0-1$ & 47 & 30 & 17 & & 29 & 18 & & 19 & 28 & \\
\hline Grade 2-3 & 37 & 23 & 14 & & 26 & 11 & & 20 & 17 & \\
\hline Dukes' stage & & & & 0.49 & & & 0.58 & & & $0.047^{\mathrm{b}}$ \\
\hline A & 8 & 6 & 2 & & 7 & 1 & & 7 & 1 & \\
\hline B & 26 & 18 & 8 & & 16 & 10 & & 13 & 13 & \\
\hline $\mathrm{C}$ & 27 & 14 & 13 & & 17 & 10 & & 12 & 15 & \\
\hline $\mathrm{D}$ & 23 & 15 & 8 & & 15 & 8 & & 7 & 16 & \\
\hline
\end{tabular}

${ }^{\mathrm{a} C}$ Clinicopathological feature, according to the TNM classification (3) and the Japanese classification of colorectal carcinoma (7). ${ }^{\mathrm{b}}$ Statistical significance between stage A and D. VEGF, vascular endothelial growth factor; TP, thymidine phosphorylase; MVD, microvessel density.

lymphatic invasion, venous invasion or budding. MVD of Dukes' stage A cases was observed to be greater than that in cases of Dukes' stage D, following performance of multiple comparison with Bonferroni correction ( $\mathrm{P}=0.0077$; Fig. 2), while there was no significant association identified between the Duke's classification, and VEGF and TP expression levels (Table I).

Correlation between VEGF, TP and MVD. The mean MVD of the high VEGF expression group was significantly greater than that of the low VEGF expression group (86.5 vs. 66.9, respectively; $\mathrm{P}=0.0194$; Fig. 3). In the 23 Dukes' stage $\mathrm{D}$ cases, the mean MVD of the high TP expression group was significantly greater than that of the low TP expression group (79.4 vs. 57.9, respectively; $\mathrm{P}=0.0149$; Fig. 4), while the mean MVD of all Dukes' stage cases demonstrated no significant difference between the high and low TP expression groups. A statistically significant correlation between the levels of VEGF and TP expression was noted $(\mathrm{r}=0.45 ; \mathrm{P}<0.0001$; Fig. 5).

Correlation between patient prognosis and VEGF, TP, and $M V C$. The patient overall survival rate in the high VEGF expression group tended to be lower when compared with that of the low VEGF expression group ( $\mathrm{P}=0.0716$; Fig. 6). In the 48 cases of lymph node metastasis, the overall survival rate of the high VEGF expression group was significantly lower than that of the low VEGF expression group $(\mathrm{P}=0.0128$; Fig. 7). However, no significant differences in the overall survival rates between the high and low TP expression groups were identified ( $\mathrm{P}=0.5169$; Fig. 8$)$, or between the high and low MVD groups $(\mathrm{P}=0.1827$; Fig. 9). 

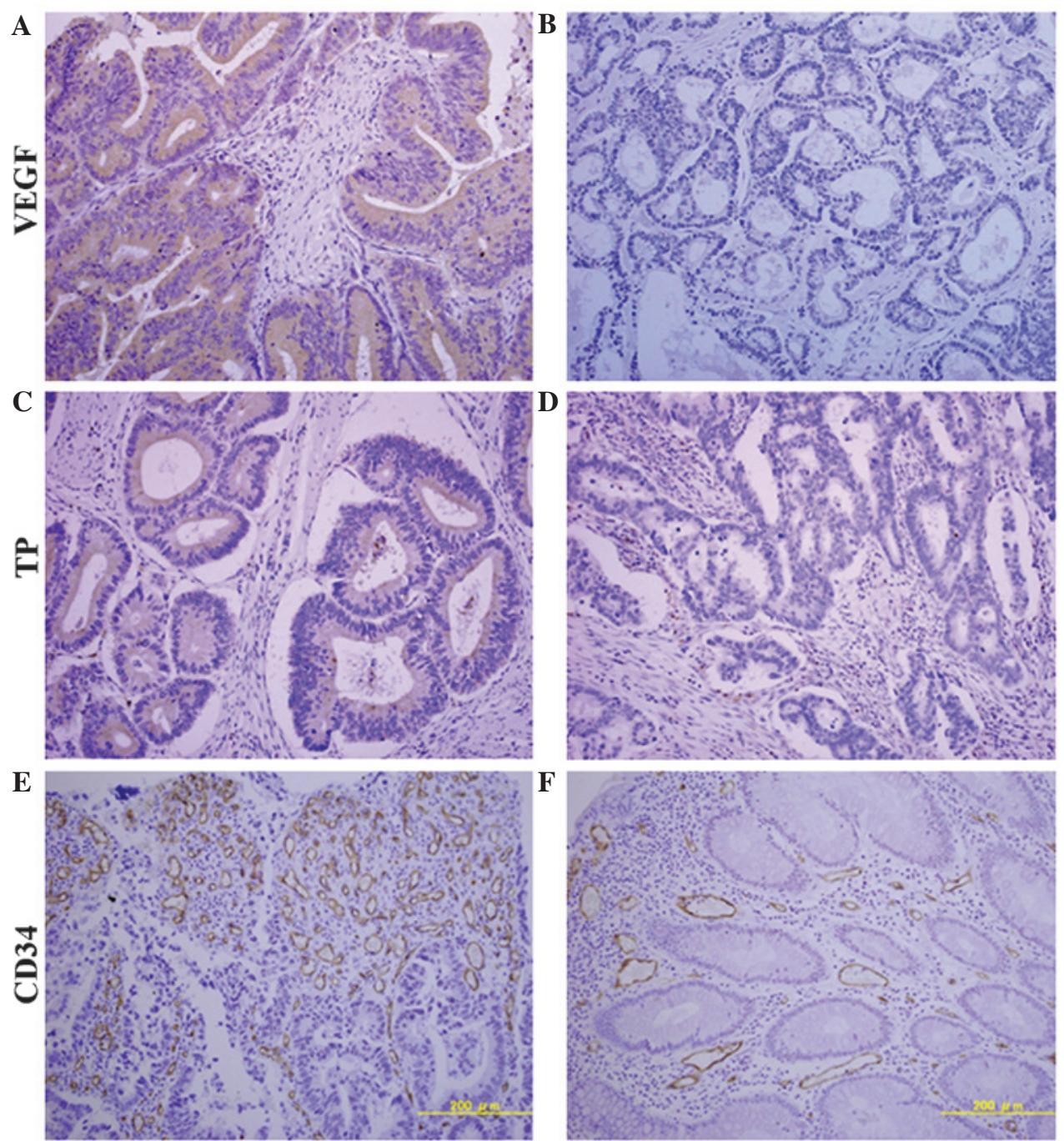

Figure 1. Immunohistochemical expression patterns of VEGF, TP and CD34 for MVD. (A) High VEGF expression, $\geq 50 \%$ staining in tumor cells. (B) Low VEGF expression, $<50 \%$ staining in tumor cells. (C) High TP expression, $\geq 50 \%$ staining in tumor cells. (D) Low TP expression, $<50 \%$ staining in tumor cells. (E) High MVD, $\geq 81.33 /$ field. (F) Low MVD, $<81.33 /$ field. Magnification, $x 20$. VEGF, vascular endothelial growth factor; TP, thymidine phosphorylase; CD34, cluster of differentiation 34; MVD, microvessel density.

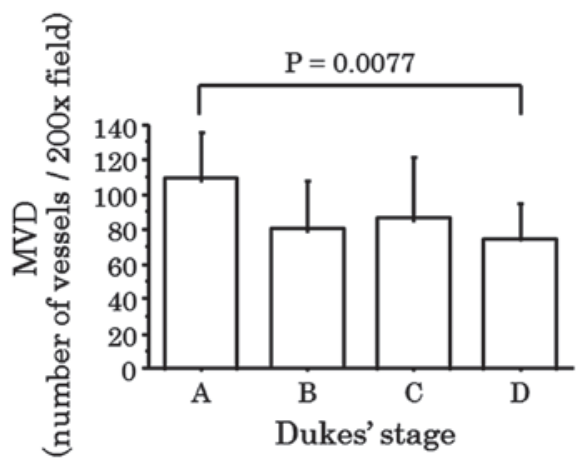

Figure 2. MVD according to the Dukes' stage. MVD of Dukes' stage A is significantly higher than that of Dukes' stage D (multiple comparison with Bonferroni correction; $\mathrm{P}=0.0077$ ). The data are expressed as the mean \pm standard deviation. MVD, microvessel density.

\section{Discussion}

Angiogenesis is essential for tumor growth and metastasis $(5,6)$. The degree of angiogenic activity in tumors was hypothesized

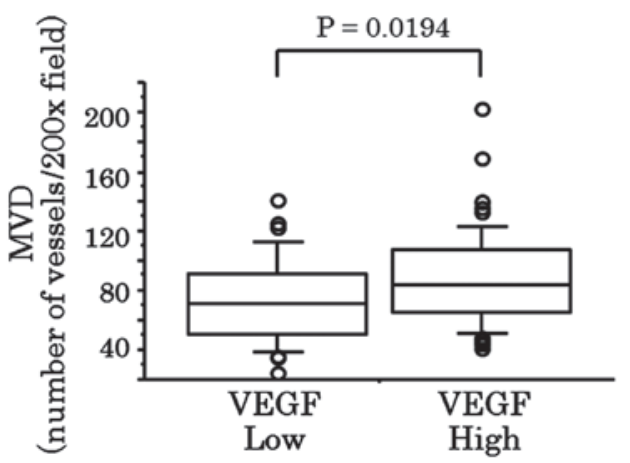

Figure 3. MVD in the high and low VEGF expression groups. The mean MVD in the high VEGF expression group was significantly greater than that of the low VEGF expression group $(\mathrm{P}=0.0194)$. The data are expressed as the mean \pm standard deviation. MVD, microvessel density; VEGF, vascular endothelial growth factor.

to define tumor aggressiveness, as a dense vascular network ensures an adequate supply of oxygen and nutrients, which facilitates tumor growth and invasion, and migration to distant 


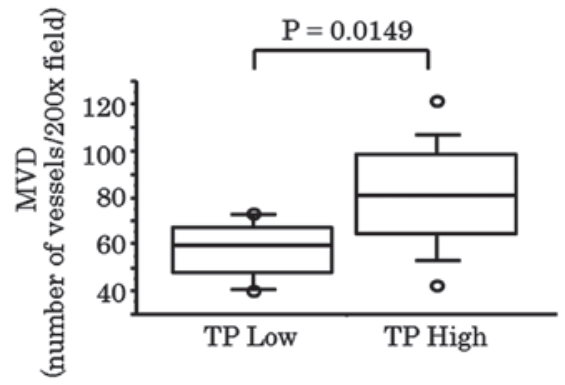

Figure 4. MVD in the high and low TP expression groups of Dukes' stage D. The mean MVD in the high TP expression group was significantly higher than that of the low TP expression group $(\mathrm{P}=0.0149)$. The data are expressed as the mean \pm standard deviation. MVD, microvessel density; TP, thymidine phosphorylase.

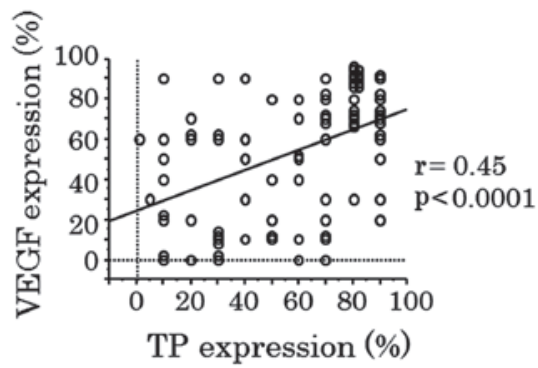

Figure 5. Correlation between the expression levels of VEGF and TP. A significant positive correlation was observed between VEGF and TP expression $(r=0.45 ; \mathrm{P}<0.0001)$. VEGF, vascular endothelial growth factor; TP, thymidine phosphorylase.

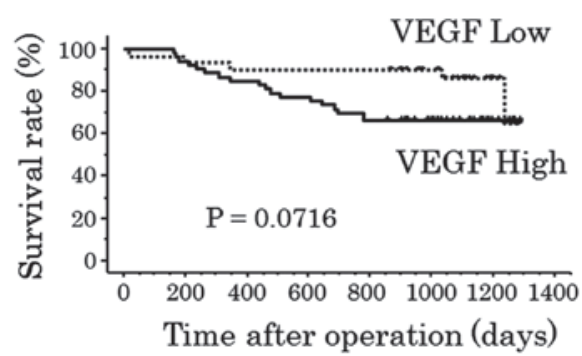

Figure 6. Patient survival rate in the high and low VEGF expression groups. The overall survival rate of the high VEGF expression group tended to be lower than that of the low VEGF expression group $(\mathrm{P}=0.0716)$. VEGF, vascular endothelial growth factor.

organs (10). Angiogenesis-stimulating proteins are commonly known as angiogenic factors and include VEGF and TP, amongst others $(4,10)$. These factors are commonly associated with increased MVD and, therefore, to an unfavorable clinical course (10). In the present study, a positive correlation was demonstrated between VEGF and TP expression levels, and an association between VEGF and TP expression and MVD was also identified. A high VEGF expression level was identified to be correlated with a short overall survival of patients exhibiting lymph node metastasis, and MVD of Dukes' stage A was observed to be significantly higher than that of Dukes' stage D.

Previous studies have described an association between VEGF expression and tumor aggressiveness in various types of malignant tumor (31), including colorectal cancer (13). Furthermore, various reports regarding colorectal cancer

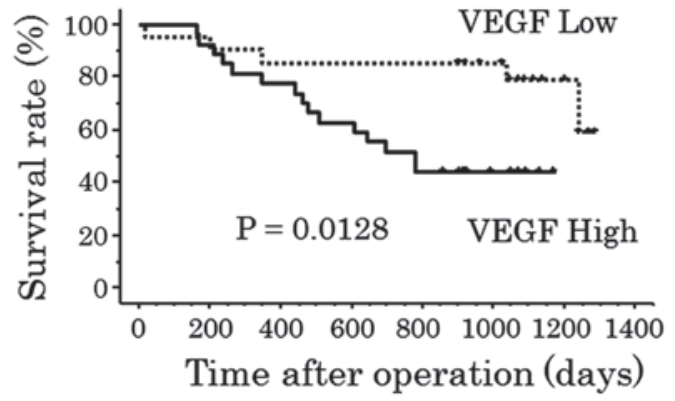

Figure 7. Survival rate of patients exhibiting lymph node metastasis, according to VEGF expression. The overall survival rate of the high VEGF expression group was significantly lower than that of the low VEGF expression group $(\mathrm{P}=0.0128)$. VEGF, vascular endothelial growth factor.

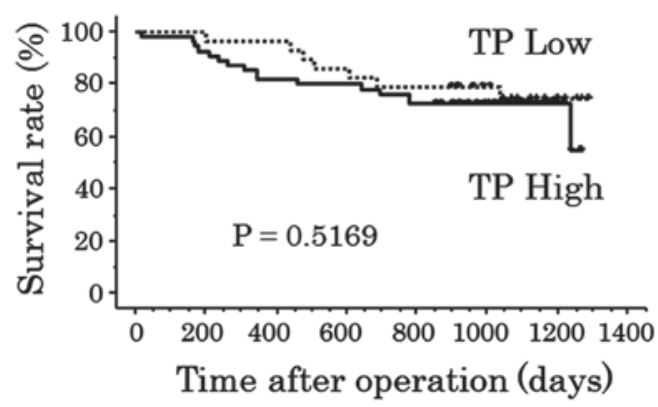

Figure 8. Patient survival rate in the high and low TP expression groups. No significant difference in overall survival rates was observed between the high and low TP expression groups $(\mathrm{P}=0.5169)$. TP, thymidine phosphorylase.

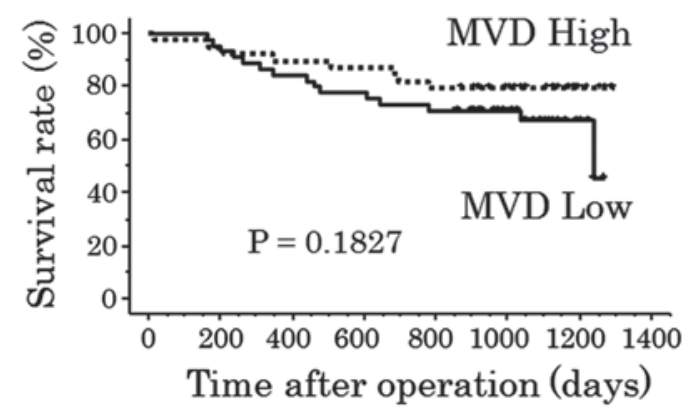

Figure 9. Patient survival rate in the high and low MVD groups. No significant difference in overall survival rates was observed between the high and low MVD groups ( $\mathrm{P}=0.1827)$. MVD, microvessel density.

specified that VEGF expression was closely correlated with tumor angiogenesis $(11,12,32)$, and may be considered an independent prognostic factor $(1,7,33)$, while a study indicated that there was no apparent correlations (12). In addition, previous reports analyzed the positive correlations between a high VEGF expression level and lymph node metastasis $(1,34)$, while certain studies revealed negative correlations $(35,36)$. In the present study, MVD in the high VEGF expression group was observed to be significantly higher than that of the low VEGF expression group, and patients' overall survival rate in the high VEGF expression group tended to be lower when compared with that of the low VEGF expression group. A high VEGF expression level is considered to be a prognostic factor of colorectal cancer, particularly in patients exhibiting lymph node metastasis. Previous studies have reported significant 
correlations between clinicopathologic features and TP expression levels $(19,35,37)$, whereas other studies have reported an inverse correlation between the TP expression level and lymph node/hematogenous metastasis (22); thus, the association between TP expression level and clinicopathologic features is considered to be controversial $(23,37-41)$. It was hypothesized in the current study that the significance of the TP expression levels is minimal with regard to angiogenesis (which is assessed by MVD), when high VEGF expression levels are sufficient to induce VEGF-associated angiogenesis.

Previous studies have demonstrated the correlations between high MVD and lymph node or distant metastases (42-47), while certain studies reported a significant correlation between MVD and hematogenous metastasis, but not with lymph node metastasis (8), and that MVD was not associated with patient survival (9). The present study demonstrated that MVD in Dukes' stage A specimens was higher than that of the Dukes' stage D specimens. Therefore, it was hypothesized that MVD is an important factor for tumor growth of primary colorectal cancer, however, exerts a less significant affect on distant metastasis, such as liver metastasis.

In conclusion, the results of the present study indicate that VEGF expression levels may serve as a prognostic factor for patients with colorectal cancer exhibiting lymph node metastasis. Furthermore, angiogenesis, as assessed by MVD, was shown to be an important prognostic factor for tumor growth at the primary site.

\section{Acknowledgements}

The present study was supported by Grants-in-Aid for Science from the Ministry of Education, Culture, Sports, Science, and Technology of Japan (Tokyo, Japan); and a Grant for Hirosaki University Institutional Research (Hirosaki, Japan).

\section{References}

1. Zafirellis K, Agrogiannis G, Zachaki A, Gravani K, Karameris A and Kombouras C: Prognostic significance of VEGF expression evaluated by quantitative immunohistochemical analysis in colorectal cancer. J Surg Res 147: 99-107, 2008.

2. Pourhoseingholi MA: Increased burden of colorectal cancer in Asia. World J Gastrointest Oncol 4: 68-70, 2012.

3. Sobin L, Gospodarowicz MK and Wittekind C: Colon and rectum. In: TNM Classification of Malignant Tumors. Sobin L, Gospodarowicz MK and Wittekind C (eds). 7th edition. Wiley-Blackwell, New York, pp100-pp105, 2009.

4. Papamichael D: Prognostic role of angiogenesis in colorectal cancer. Anticancer Res 21: 4349-4353, 2001.

5. Folkman J: What is the evidence that tumors are angiogenesis dependent? J Natl Cancer Inst 82: 4-6, 1990.

6. Folkman J, Watson K, Ingber D and Hanahan D: Induction of angiogenesis during the transition from hyperplasia to neoplasia. Nature 339: 58-61, 1989.

7. Des Guetz G, Uzzan B, Nicolas P, Cucherat M, Morere JF, Benamouzig R, Breau JL and Perret GY: Microvessel density and VEGF expression are prognostic factors in colorectal cancer. Meta-analysis of the literature. Br J Cancer 94: 1823-1832, 2006.

8. Tanigawa N, Amaya H, Matsumura M, Lu C, Kitaoka A, Matsuyama K and Muraoka R: Tumor angiogenesis and mode of metastasis in patients with colorectal cancer. Cancer Res 57: 1043-1046, 1997.

9. Gao J, Knutsen A, Arbman G, Carstensen J, Frånlund B and Sun XF: Clinical and biological significance of angiogenesis and lymphangiogenesis in colorectal cancer. Dig Liver Dis 41: 116-122, 2009.

10. Giatromanolaki A, Sivridis E and Koukourakis MI: Angiogenesis in colorectal cancer: Prognostic and therapeutic implications. Am J Clin Oncol 29: 408-417, 2006.
11. Amaya H, Tanigawa N, Lu C, Matsumura M, Shimomatsuya T, Horiuchi T and Muraoka R: Association of vascular endothelial growth factor expression with tumor angiogenesis, survival and thymidine phosphorylase/platelet-derived endothelial cell growth factor expression in human colorectal cancer. Cancer Lett 119: 227-235, 1997.

12. Zheng S, Han MY, Xiao ZX, Peng JP and Dong Q: Clinical significance of vascular endothelial growth factor expression and neovascularization in colorectal carcinoma. World J Gastroenterol 9: 1227-1230, 2003.

13. Ishigami SI, Arii S,Furutani M,Niwano M,Harada T,Mizumoto M, Mori A, Onodera $\mathrm{H}$ and Imamura M: Predictive value of vascular endothelial growth factor (VEGF) in metastasis and prognosis of human colorectal cancer. Br J Cancer 78: 1379-1384, 1998.

14. Cascinu S, Staccioli MP, Gasparini G, Giordani P, Catalano V, Ghiselli R, Rossi C, Baldelli AM, Graziano F, Saba V, et al: Expression of vascular endothelial growth factor can predict event-free survival in stage II colon cancer. Clin Cancer Res 6: 2803-2807, 2000.

15. Furukawa T, Yoshimura A, Sumizawa T, Haraguchi M, Akiyama S, Fukui K, Ishizawa M and Yamada Y: Angiogenic factor. Nature 356: 668, 1992.

16. Ishikawa F, Miyazono K, Hellman U, Drexler H, Wernstedt C, Hagiwara K, Usuki K, Takaku F, Risau W and Heldin CH: Identification of angiogenic activity and the cloning and expression of platelet-derived endothelial cell growth factor. Nature 338: 557-562, 1989.

17. Ciccolini J, Evrard A and Cuq P: Thymidine phosphorylase and fluoropyrimidines efficacy: A Jekyll and Hyde story. Curr Med Chem Anticancer Agents 4: 71-81, 2004.

18. Folkman J: What is the role of thymidine phosphorylase in tumor angiogenesis. J Natl Cancer Inst 88: 1091-1092, 1996.

19. Takebayashi Y, Akiyama S, Akiba S, Yamada K, Miyadera K, Sumizawa T, Yamada Y, Murata F and Aikou T: Clinicopathologic and prognostic significance of an angiogenic factor, thymidine phosphorylase, in human colorectal carcinoma. J Natl Cancer Inst 88: 1110-1117, 1996.

20. Takahashi Y, Bucana CD, Liu W, Yoneda J, Kitadai Y, Cleary KR and Ellis LM: Platelet-derived endothelial cell growth factor in human colon cancer angiogenesis: Role of infiltrating cells. J Natl Cancer Inst 88: 1146-1151, 1996.

21. Matsuura T, Kuratate I, Teramachi K, Osaki M, Fukuda Y and Ito $\mathrm{H}$ : Thymidine phosphorylase expression is associated with both increase of intratumoral microvessels and decrease of apoptosis in human colorectal carcinomas. Cancer Res 59: 5037-5040, 1999.

22. Saito S, Tsuno N, Nagawa H, Sunami E, Zhengxi J, Osada T, Kitayama J, Shibata Y, Tsuruo T and Muto T: Expression of platelet-derived endothelial cell growth factor correlates with good prognosis in patients with colorectal carcinoma. Cancer 88: 42-49, 2000.

23. van Triest B, Pinedo HM, Blaauwgeers JL, van Diest PJ, Schoenmakers PS, Voorn DA, Smid K, Hoekman K, Hoitsma HF and Peters GJ: Prognostic role of thymidylate synthase, thymidine phosphorylase/platelet-derived endothelial cell growth factor and proliferation markers in colorectal cancer. Clin Cancer Res 6: 1063-1072, 2000

24. van Halteren HK, Peters HM, van Krieken JH, Coebergh JW, Roumen RM, van der Worp E, Wagener JT and Vreugdenhil G: Tumor growth pattern and thymidine phosphorylase expression are related with the risk of hematogenous metastasis in patients with Astler Coller B1/B2 colorectal carcinoma. Cancer 91: 1752-1757, 2001.

25. Locker GY, Hamilton S, Harris J, Jessup JM, Kemeny N, Macdonald JS, Somerfield MR, Hayes DF and Bast RC Jr; ASCO: ASCO 2006 update of recommendations for the use of tumor markers in gastrointestinal cancer. J Clin Oncol 24: 5313-5327, 2006.

26. Mainprize KS, Mortensen NJ and Warren BF: Dukes' staging is poorly understood by doctors managing colorectal cancer. Ann R Coll Surg Engl 84: 23-25, 2002.

27. General Assembly of the World Medical Association: World medical association declaration of Helsinki: Ethical principles for medical research involving human subjects. J Am Coll Dent 81: 14-18, 2014.

28. Japanese Society for Cancer of the Colon and Rectum. Japanese classification of colorectal carcinoma. Second English Edition. Kanehara \& Co., Lit., Tokyo, 2009.

29. Ueno H, Murphy J, Jass JR, Mochizuki H and Talbot IC: Tumour 'budding' as an index to estimate the potential of aggressiveness in rectal cancer. Histopathology 40: 127-132, 2002. 
30. Bosari S, Lee AK, DeLellis RA, Wiley BD, Heatley GJ and Silverman ML: Microvessel quantitation and prognosis in invasive breast carcinoma. Hum Pathol 23: 755-761, 1992.

31. O'Byrne KJ, Koukourakis MI, Giatromanolaki A, Cox G, Turley H, Steward WP, Gatter K and Harris AL: Vascular endothelial growth factor, platelet-derived endothelial cell growth factor and angiogenesis in non-small-cell lung cancer. $\mathrm{Br}$ J Cancer 82: 1427-1432, 2000.

32. Takahashi Y, Tucker SL, Kitadai Y, Koura AN, Bucana CD, Cleary KR and Ellis LM: Vessel counts and expression of vascular endothelial growth factor as prognostic factors in node-negative colon cancer. Arch Surg 132: 541-546, 1997.

33. Ogata Y, Matono K, Mizobe T, Ishibashi N, Mori S, Akagi Y, Ikeda S, Ozasa H, Murakami H and Shirouzu K: The expression of vascular endothelial growth factor determines the efficacy of post-operative adjuvant chemotherapy using oral fluoropyrimidines in stage II or III colorectal cancer. Oncol Rep 15: 1111-1116, 2006.

34. George ML, Tutton MG, Janssen F, Arnaout A, Abulafi AM, Eccles SA and Swift RI: VEGF-A, VEGF-C and VEGF-D in colorectal cancer progression. Neoplasia 3: 420-427, 2001.

35. Yoshimoto K, Kawahara H, Kobayashi S, Kashiwagi H, Hirai $\mathrm{K}$ and Yanaga K: Importance of thymidine phosphorylase expression at the invasive front of $\mathrm{T} 3$ rectal cancer as a prognostic factor. Dig Surg 23: 331-335, 2006

36. Abdou AG, Aiad H, Asaad N, Abd El-Wahed M and Serag El-Dien M: Immunohistochemical evaluation of vascular endothelial growth factor (VEGF) in colorectal carcinoma. J Egypt Natl Canc Inst 18: 311-322, 2006.

37. Aoki T, Katsumata K, Tsuchida A, Tomioka H and Koyanagi Y: Correlation between malignancy grade and p53 gene in relation to thymidine phosphorylase activity in colorectal cancer patients. Oncol Rep 9: 1267-1271, 2002.

38. Tsuji T, Sawai T, Yamashita H, Takeshita H, Nakagoe T, Shindou H, Fukuoka H, Yoshinaga M, Hidaka S, Yasutake T, et al: Platelet-derived endothelial cell growth factor expression is an independent prognostic factor in colorectal cancer patients after curative surgery. Eur J Surg Oncol 30: 296-302, 2004.

39. Matsumura M, Chiba Y, Lu C, Amaya H, Shimomatsuya T, Horiuchi T, Muraoka R and Tanigawa N: Platelet-derived endothelial cell growth factor/thymidine phosphorylase expression correlated with tumor angiogenesis and macrophage infiltration in colorectal cancer. Cancer Lett 128: 55-63, 1998.
40. Osanai T, Ichikawa W, Takagi Y,Uetake H, Nihei Z and Sugihara K: Expression of pyrimidine nucleoside phosphorylase (PyNPase) in colorectal cancer. Jpn J Clin Oncol 31: 500-505, 2001.

41. Tokunaga Y, Hosogi H, Hoppou T, Nakagami M, Tokuka A and Ohsumi K: Prognostic value of thymidine phosphorylase/platelet-derived endothelial cell growth factor in advanced colorectal cancer after surgery: Evaluation with a new monoclonal antibody. Surgery 131: 541-547, 2002.

42. Takebayashi Y, Aklyama S, Yamada K, Akiba S and Aikou T: Angiogenesis as an unfavorable prognostic factor in human colorectal carcinoma. Cancer 78: 226-231, 1996.

43. Cianchi F, Palomba A, Messerini L, Boddi V, Asirelli G, Perigli G, Bechi P, Taddei A, Pucciani F and Cortesini C: Tumor angiogenesis in lymph node-negative rectal cancer: Correlation with clinicopathological parameters and prognosis. Ann Surg Oncol 9: 20-26, 2002.

44. Nakayama Y, Nagashima N, Minagawa N, Inoue Y, Katsuki T, Onitsuka K, Sako T, Hirata K, Nagata N and Itoh H: Relationships between tumor-associated macrophages and clinicopathological factors in patients with colorectal cancer. Anticancer Res 22 4291-4296, 2002.

45. Rajaganeshan R, Prasad R, Guillou PJ, Chalmers CR, Scott N, Sarkar R, Poston G and Jayne DG: The influence of invasive grow th pattern and microvessel density on prognosis in colorectal cancer and colorectal liver metastases. Br J Cancer 96: 1112-1117, 2007.

46. Kaneko I, Tanaka S, Oka S, Yoshida S, Hiyama T, Arihiro K, Shimamoto F and Chayama K: Immunohistochemical molecular markers as predictors of curability of endoscopically resected submucosal colorectal cancer. World J Gastroenterol 13: 3829-3835, 2007.

47. Yan G, Zhou XY, Cai SJ, Zhang GH, Peng JJ and Du X: Lymphangiogenic and angiogenic microvessel density in human primary sporadic colorectal carcinoma. World J Gastroenterol 14: 101-107, 2008 